\title{
SOCIEDADES CIENTÍFICAS, ¿GENERAN CIENCIA DURANTE ELL PREGRADO?
}

\author{
Scientific Societies, do they generate science \\ during undergraduate?. \\ Gisela Mabel Vargas¹.
}

Actualmente se puede observar que el estudiante de medicina durante su estadía en pregrado, tiene el deseo de buscar respuestas y dar soluciones a problemas existentes en la población; sin embargo aún no podemos hablar de una formación adecuada en metodología de la investigación que pueda resolver tales exigencias, este sigue siendo un punto débil en las mayas curriculares de las distintas Universidades en Latinoamérica junto con las limitaciones que se presentan para que un estudiante de pregrado pueda iniciar, realizar y concluir la investigación, lanzándonos datos de la tan baja producción en trabajos científicos de Latinoamérica ${ }^{1,2}$.

El no contar con asesoría apropiada, puede ser una de las varias limitantes, solo por el hecho de no conocer con quién acudir y guíe correctamente todo el trabajo de investigación a realizarse, además de no contar con el financiamiento adecuado si se lo llega a necesitar, que el trabajo realizado no sea reconocido, la falta de incentivos por parte de las Universidades, entre otras ${ }^{1}$.

Todo esto hace que el estudiante busque la forma de saciar su falta de información y fomentar sus capacidades científicas, para tal efecto es que se crean las Sociedades Científicas de Estudiantes de Medicina (SOCEM) a mediados de los noventa, los cuales cuentan con el espacio académico-científico necesario para poder cubrir todas estas necesidades ${ }^{2}$.

Entre sus objetivos resalta el ámbito científico investigativo brindando a los estudiantes las herramientas necesarias para que engrandezcan sus capacidades científicas, de manera que vayan ejercitándolas en cursos/ talleres, presentación a congresos locales, nacionales e internacionales y claro está esperando que el trabajo presentado termine en la publicación del mismo en una revista científica, además que buscan que el estudiante también tenga una visión en atención integral en salud y elevar el nivel de educación ${ }^{2,3}$.

Para poder lograr esto, las SOCEM cuentan con asesores capacitados que puedan brindar la asistencia necesaria y así crear una cultura científica en los estudiantes, que empezarán a realizar trabajos de investigación, artículos científicos como son: casos clínicos, imágenes médicas, cartas al editor, etc. Siempre impulsando a que también tengan la costumbre de que todos estos trabajos concluyan en la publicación ${ }^{4}$.

Las SOCEM no solo actúan de manera local, sino que también lo hacen de manera nacional e internacional como lo es la Federación Latinoamericana de Sociedades Científicas de Estudiantes de Medicina FELSOCEM, lo que asegura el fomento y desarrollo científico investigativo y educación médica continua en atención integral en salud ${ }^{3}$.

Debido a su arduo trabajo deben de plantearse debilidades y adversidades que pueden ocurrir, tener presente que siempre debe existir una capacitación continua de nuevos estudiantes investigadores salvaguardando la producción científica, realizar actividades como simposios, congresos, etc. que ayuden a la actualización médica ${ }^{5}$.

El hecho de pertenecer a una SOCEM, no es un indicativo de que todos sus socios realmente lleguen a generar producción científica, sin embargo al brindar bastantes oportunidades hacen que se cree una cultura científica en los estudiantes de pregrado realizando con mayor frecuencia trabajos y proyectos de investigación mejorando sus capacidades científicas (redacción científica, análisis estadístico, buen manejo metodológico) ${ }^{2}$ ampliando su curriculum con publicaciones que pueden llegar a ser citadas por su relevancia, originalidad y calidad.

Por todo lo anteriormente comentado es que las SOCEM, crean el ambiente científico-académico apropiado que fortalecen y ayudan al desarrollo de las capacidades científicas de cada socio, otorgando oportunidades y herramientas con las cuales pueden trabajar en favor de la producción científica, además es de conocimiento que muchos de los investigadores reconocidos actualmente y profesionales destacados pertenecieron a una SOCEM durante su formación en el pregrado, e inclusive siguen siendo parte de los mismos como asesores y mentores de nuevos jóvenes investigadores.

\section{REFERENCIAS}

1.Cvetkovic A, Inga F, Mestas C. Organizaciones científicas estudiantiles como semilleros de líderes y gestores de la investigación científica en el Perú: SOCIMEP. Acta Med Peru. 2016;34(1):70-1. Disponible en: http://www.scielo.org.pe/pdf/amp/v34n1/a14v34n1.pdf. 2.Mejia $\mathrm{CR}$, et al. Participación en una sociedad científica de estudiantes de Medicina asociada a la producción científica extracurricular en Latinoamérica. Educ Med. 2018. Disponible en: https://doi.org/10.1016/j.edumed.2017.10.014. 3.Ortiz Y. Rol de las sociedades científica en la investigación médica estudiantil en Colombia. Rev Cient Cienc Med 2016; 19(1):66-67. Disponible en: http://www.scielo.org.bo/pdf/rccm/v19n1/v19n1_a15.pdf. 
4.Ortiz Y, Bados D, Suárez L. Oportunidades de investigación ofrecidas por las sociedades científicas de estudiantes de medicina. FEM. 2017;20(1):41. Disponible en: https:// dialnet.unirioja.es/servlet/articulo? codigo $=5819878$. 5.Quispe C, Velásquez L, Meza J, Fernández J. ¿Cómo impulsar una sociedad científica de estudiantes de medicina?. Educ Med. 2018. Disponible en: https://www. sciencedirect.com/science/article/pii/S1575181318300718.

\section{Gisela Mabel Vargas ${ }^{1}$}

${ }^{1}$ Editor Revista Científica "Ciencia Médica".

Sociedad Científica de Estudiantes de Medicina,

Facultad de Medicina "Dr. Aurelio Melean",

Universidad Mayor de San Simón.

Cochabamba-Bolivia

Correspondencia: gisel090193@gmail.com 